\title{
THE IMPACTS OF SUPPLIERS
}

AND MUTUAL OUTSOURCING ON ORGANIZATIONAL FORMS

\author{
Yasuhiro Arai \\ Noriaki Matsushima
}

December 2021

The Institute of Social and Economic Research

Osaka University

6-1 Mihogaoka, Ibaraki, Osaka 567-0047, Japan 


\title{
The impacts of suppliers and mutual outsourcing on organizational forms*
}

\author{
Yasuhiro Arai ${ }^{\dagger}$ \\ Faculty of Humanities and Social Sciences, Kochi University \\ Noriaki Matsushima ${ }^{\ddagger}$ \\ Institute of Social and Economic Research, Osaka University
}

December 28, 2021

\begin{abstract}
We consider a downstream duopoly model with a monopolistic common supplier and mutual outsourcing between the two symmetric downstream firms. The market structure captures the recent procurement environment in the smartphone industry. We also incorporate managerial delegations into the duopoly model because deciding on organizational forms within a firm is critical to achieving better performance in almost all industries. There is an equilibrium in which only one of the firms delegates its downstream production to its sales manager. A delegating firm becomes less aggressive. The profits when both firms delegate can be higher than those when no firm delegates. The total surplus when both firms delegate is smaller than that when no firm delegates.
\end{abstract}

Keywords: Mutual outsourcing, Supplier, Delegation, Asymmetric managerial forms. JEL Codes: L13, D43.

\footnotetext{
${ }^{*}$ We are thankful to Michael Kopel for his invaluable comments and suggestions. We gratefully acknowledge the financial support from the Japan Society for the Promotion of Science (JSPS), KAKENHI Grant Numbers JP15H03349, JP15H05728, JP17H00984, JP18H00847, JP18K01593, JP19H01483, and JP20H05631. Although Matsushima serves as a member of the Competition Policy Research Center (CPRC) at Japan Fair Trade Commission (JFTC), our paper does not reflect the views of JFTC. The usual disclaimer applies.

${ }^{\dagger}$ Yasuhiro Arai, Faculty of Humanities and Social Sciences, Kochi University, 2-5-1 Akebono-cho, Kochi-shi, Kochi 780-8520 JAPAN. E-mail: yasuhiro68@gmail.com

${ }^{\ddagger}$ Corresponding author: Noriaki Matsushima, Institute of Social and Economic Research, Osaka University, Mihogaoka 6-1, Ibaraki, Osaka 567-0047, Japan. E-mail: nmatsush@iser.osaka-u.ac.jp
} 


\title{
The impacts of suppliers and mutual outsourcing on organizational forms
}

\begin{abstract}
We consider a downstream duopoly model with a monopolistic common supplier and mutual outsourcing between the two symmetric downstream firms. The market structure captures the recent procurement environment in the smartphone industry. We also incorporate managerial delegations into the duopoly model because deciding on organizational forms within a firm is critical to achieving better performance in almost all industries. There is an equilibrium in which only one of the firms delegates its downstream production to its sales manager. A delegating firm becomes less aggressive. The profits when both firms delegate can be higher than those when no firm delegates. The total surplus when both firms delegate is smaller than that when no firm delegates.
\end{abstract}

Keywords: Mutual outsourcing, supplier, delegation, asymmetric managerial forms.

JEL Codes: L13, D43. 


\section{Introduction}

Deciding on organizational forms within a firm is critical to achieving better performance in almost all industries (Foss and Klein, 2014). When firms consider their optimal organizational forms, they need to consider internal resources (Mosakowski, 1998), suppliers (Bolandifar et al., 2016), customers (Foss et al., 2011), competitors (Fershtman and Judd, 1987), technological knowledge (Foss et al., 2013), and so on. In particular, we need to focus on the effects of supplier relations and technological knowledge on firms' internal organization forms because the evolution of technological complexity in many industries has augmented firms' dependency on outside resources (Bolandifar et al., 2016). Therefore, we investigate the organizational forms of firms by taking into account the key elements in the manufacturing industry: the monopolistic supplier and the mutual outsourcing. Below, we explain why we identified these two elements as the key factors in the manufacturing industry, particularly focusing on the smartphone industry, which provides items essential for daily life, as an example.

Mutual outsourcing has become a common business practice in technology-intensive industries, typically the smartphone industry. ${ }^{1}$ For instance, Google and Samsung mutually outsource their key components to each other. ${ }^{2}$ Samsung produces the Nexus smartphone for Google as an original equipment manufacturer (OEM). Google manages the Android operating system, which is a critical component for smartphone operation. This operating system powers the Nexus smartphone sold by Google to final consumers. Samsung also embeds the Android operating system into its Galaxy smartphone and sells the smartphone to final consumers. In sum, Google and Samsung mutually depend

\footnotetext{
${ }^{1}$ Pun (2015) and Milliou and Serfes (2020) provide some real-world examples of mutual outsourcing in some industries.

${ }^{2}$ We borrowed this example from Pun (2015, p.2092).
} 
on each other to produce their smartphones.

Along with such mutual outsourcing, in the input market for smartphones, Qualcomm plays an indispensable role and exerts strong monopoly power over the smartphone makers including Apple, Google, and Samsung. ${ }^{3}$ Qualcomm produces global 4G modem chips, which are a vital input for smartphones. Qualcomm held more than half the market share in the modem chip industry in 2017 (Ai and Lu, 2019, p.645).

Qualcomm demanded that Apple's OEMs pay royalty fees that are higher than the standard-essential patent (SEP) royalty fees (see Ai and Lu, 2019, p.647), although the royalty rates of Qualcomm's SEPs for 4G cellular technologies are nominally inflexible under the committed terms based on the FRAND (fair, reasonable, and nondiscriminatory) licenses. Any refusal to this demand would lead to Qualcomm's refusal to supply its modem chip to the refusing OEM. ${ }^{4}$ Altogether, Qualcomm exerts its monopoly power in various ways in the modem chip market (see the discussions on antitrust concerns in Hovenkamp (2017) and Hovenkamp and Simcoe (2020)).

Given the current technological environment mentioned above, we consider a downstream duopoly model with a monopolistic common supplier and mutual outsourcing between the two downstream firms. ${ }^{5}$ We also incorporate managerial delegations into the duopoly model, as in Fershtman and Judd (1987), Sklivas (1987), and Basu (1995), and derive the equilibrium managerial structure (see excellent surveys on strategic del-

\footnotetext{
${ }^{3}$ Although Samsung is also a modem chip maker, it has depended on Qualcomm to produce its high-end smartphones (see, for instance, Srivastava (2016) and Leswing (2019)).

${ }^{4}$ Practitioners often refer to this as the "no license, no chip policy."

${ }^{5}$ Our analytical framework would also apply to the automobile industry because mutual outsourcing is a common practice. For instance, competitors Nissan and Daimler mutually traded their car components (Pun, 2015). On the one hand, Nissan produced its luxury car, Infinity, by purchasing the front-wheel-drive architecture platform used in Daimler's Mercedes. On the other hand, Nissan supplied diesel and gas engines to Daimler. Automobile manufacturers depend on suppliers in oligopolistic industries, including tires, glass, and so on.
} 
egation by Sengul et al. (2012), Lambertiti (2017), and Kopel and Pezzino (2018); empirical analysis of delegation, Colombo et al. (2007) and Bloomfield (2021)).

The downstream firms compete in quantity, which is suitable for investigating competition in the manufacturing industries (see, e.g., Sundaram et al., 1996; PlehnDujowich and Serfes, 2010). In the smartphone industry, production capacity constraints in input markets (e.g., modem chip production) can be a bottleneck to producing enough smartphones (see, for instance, Sohn, 2021, a recent article about the global chip shortage). The downstream firms mutually outsource their inputs from the rivals under linear input prices, where the per-unit payment is constant with respect to the procuring input quantity. The monopolistic input supplier sells its key input to the two downstream firms under a common linear input price. ${ }^{6}$ Each downstream firm produces one unit of the final product by combining each one unit of those three inputs.

In the first stage, each downstream firm's owner determines whether to delegate its decision regarding the downstream production to a manager. ${ }^{7}$ If the owner delegates, the firm needs to incur a fixed operational cost to inspect the manager's performance, as in Basu (1995). In the second stage, the monopoly supplier and the owners set the contract terms in the input market regardless of the managerial forms determined in the first stage. In the third stage, each owner offers an incentive contract to the manager if she/he delegates in the first stage. The incentive contract in each firm consists of a linear combination of its profit and revenue (Fershtman and Judd, 1987). In the fourth stage, the decision-makers in the downstream market simultaneously set their quantities.

First, we show that the delegating owner places a negative weight on the revenue in

\footnotetext{
${ }^{6}$ We obtain a qualitatively similar result even when the supplier can price discriminate against the downstream firms.

${ }^{7}$ We explain the plausibility of the timing structure in Section 3.
} 
the linear combination of the incentive contract to its manager, inducing the manager to be less aggressive than an owner-managed firm. Second, we also show that there are three types of equilibrium managerial structures depending on the fixed operational cost in the case of delegation: (i) no owner delegates; (ii) only one owner delegates; (iii) both owners delegate. Because the manager is less aggressive than an owner-managed firm, the sum of the quantities supplied in case (i) is the largest. This comparison implies that the consumer surplus in case (i) is the largest.

The logic behind the first result is different from those in several papers related to strategic delegation (e.g., labor union (Szymanski, 1994) and monopoly supplier (Liao, 2010)) but similar to that in Macho-Stadler and Verdier (1991), who consider crossshareholdings, although the realized result is similar to those in the former related papers.

The logic behind the second result is new in the context of strategic delegation. ${ }^{8}$ The second result implies that mimicking the well-performed rival's organizational form can be an inconsiderate decision. Related to the result, the well-known facts are that Samsung is more likely to employ centralized management (Joseph et al., 2016) and that Google is more likely to employ delegated management (Steiber, 2014). Following our second result, we can conclude that the co-existence of asymmetric managerial forms is a considerable consequence. Note that the interaction of the two essential elements (the monopolistic supplier and mutual outsourcing) is the key to obtaining our result.

We explain the intuition behind the results. In our model, there are two forces that influence incentive contracts: (i) the downstream firms' input prices in mutual outsourcing and (ii) the supplier's input price. In the fourth stage, when the decision-

\footnotetext{
${ }^{8}$ Several papers also show asymmetric managerial structures in different contexts (Vroom, 2006; Mujumdar and Pal, 2007; Kopel and Löffler, 2008, 2012; Pan et al., 2020). We explain the difference between those papers and ours in Section 2.
} 
makers set their quantities, they do not take into account their revenues from the input market, as in the standard quantity competition with internal market licensing (e.g., Faulí-Oller and Sandonís, 2002, p.195). However, when they mutually outsource, each of the firms gains a larger licensing revenue if it is less aggressive in the downstream market. The delegating owner can internalize the licensing revenue by offering an incentive contract that makes its manager less aggressive than an owner-managed firm. Concretely, the delegating owner sets a negative weight on the revenue in the linear combination of the incentive contract. The monopolistic supplier does not have any key role in the establishment of the first main result, which is in contrast to the related papers whose timing structures differ from ours (Szymanski, 1994; Liao, 2010).

Now, considering the asymmetric managerial structure, we explain the intuition behind the second main result. The delegating owner enjoys a lower input price offered by the competing owner because the rival nondelegating owner anticipates that the delegating owner makes its manager less aggressive than an owner-managed firm. Such a lower input price offered by the nondelegating owner allows the monopolistic supplier to offer a higher input price because of the strategic substitution in the complementary input market. The monopoly power of the supplier is strongest when no firm delegates because each firm gives priority to the profit from the downstream market. Because of the rent extraction by the monopolistic supplier, the asymmetric managerial structure can be attainable if the cost of delegation is moderate.

The interaction of the two forces mentioned above is important for obtaining the asymmetric managerial structure because the negative weight in the incentive contract stems from the first force mentioned above. Note that in the asymmetric managerial structure in which only one owner decides to delegate, the firm with delegation supplies 
the same quantity as that without delegation in equilibrium. ${ }^{9}$ The equilibrium quantity of the delegating firm implies that the input price reduction through delegation provides an advantage to the delegating firm. Furthermore, the firm with delegation earns a higher profit than that without delegation when the asymmetric managerial structure occurs on the equilibrium path.

The remainder of this paper is organized as follows. Section 2 surveys the related papers. Section 3 constructs the model. Section 4 analyzes the three subgames and shows the main result. Section 5 discusses how the two key elements in our model affect the analytical results. Section 6 offers concluding remarks.

\section{Related papers}

Several papers show the possibility of making managers less aggressive than ownermanaged firms (e.g., vertical relations (e.g., Szymanski, 1994; Liao, 2010; Habiger and Kopel, 2020), network externalities (e.g., Hoernig, 2012; Lee and Choi, 2018)). ${ }^{10}$ Szymanski (1994) incorporates firm-specific labor unions into the standard duopoly model with delegation. His numerical analysis shows that delegating firms are less aggressive than profit-maximizing firms because these delegating firms anticipate that the labor unions extract rents after the determination of incentive contracts. ${ }^{11}$ The different timing structure is the key to deriving such less aggressive behavior.

Although most of those papers with vertical relations do not investigate the equi-

\footnotetext{
${ }^{9}$ If the supplier can price discriminate, the delegating firm supplies a larger quantity than the owner-managed firm in equilibrium.

${ }^{10}$ Liao (2014) and Claude (2018) extend Liao (2010). Fanti and Scrimitore (2019) consider a duopoly model where a vertically integrated firm and an independent downstream firm that procures inputs from the integrated firm compete in quantity. Vertical integration is the key in their model to obtaining the negative weight on the sales volume in equilibrium.

${ }^{11}$ Fanti and Meccheri (2013) and Chatterjee and Saha (2017) further investigate the model framework in Szymanski (1994).
} 
librium managerial structure, Choi et al. (2020) is the exception. They investigate endogenous managerial forms in duopoly models with two exclusive vertical relations. They show that employing managerial delegation is a dominant strategy, which contrasts with our result. Even if they also assume that a delegating firm incurs a fixed operational cost to inspect the manager's performance, as in Basu (1995) and our paper, an asymmetric managerial structure does not appear. ${ }^{12}$

Some theoretical studies have investigated how strategic organizational design affects firm asymmetry (Vroom, 2006; Mujumdar and Pal, 2007; Kopel and Löffler, 2008, 2012; Pan et al., 2020). ${ }^{13}$ The stream of this research interprets the organizational design as a commitment device for firms' output decisions. Specifically, when a firm's owner hires a manager with an incentive contract, the owner can make the manager more/less aggressive through the contract terms than an owner-managed firm.

Vroom (2006) discusses a duopoly market where a firm's owner offers a relativeperformance-based incentive contract to the (downstream) marketing manager. Initially, if the owner of a firm decides to decentralize vertically, the (upstream) production manager determines the internal transfer price after the decisions regarding the incentive contracts for the marketing managers in the two firms. If not, the internal transfer price is set equal to the marginal cost of the firm. That is, regardless of organizational choices, the two owners offer incentive contracts to their marketing managers.

He shows the possibility that one owner chooses decentralization and the other chooses centralization. In this asymmetric case, the stronger the centralized firm's

\footnotetext{
12 We check it by comparing $\pi_{i}^{d d C}-\pi_{i}^{n d C}$ (the gross gain from delegation given that the rival delegates) and $\pi_{i}^{d n C}-\pi_{i}^{n n C}$ (the gross gain from delegation given that the rival does not delegate) in their paper, and find that $\left(\pi_{i}^{d d C}-\pi_{i}^{n d C}\right)>\left(\pi_{i}^{d n C}-\pi_{i}^{n n C}\right)$, implying that an asymmetric managerial structure does not appear.

13 Recently, Macho-Stadler et al. (2021) discuss a downstream duopoly with technological spillovers and show an equilibrium asymmetric managerial structure. The key factor is the interaction between the modes of downstream competition and the strategic nature of R\&D investments.
} 
aggressiveness, the lower the decentralized firm's internal transfer price because the decentralized firm needs to maintain its demand by lowering the internal transfer price. Anticipating the decentralized firm's retaliation through lowering its transfer price, the centralized firm sets the least aggressive incentive contract, mitigating the downstream competition.

In the asymmetric case, the decentralized firm acquires an advantage (the relative aggressiveness in the downstream market) and a disadvantage (the double mark-up problem). The two contrasting effects make the asymmetric organizational forms attainable. That is, internal transfer pricing is the key to obtaining the asymmetric case, although external sourcing is out of scope in Vroom (2006).

Our paper provides a different source of balancing the two firms' competitive advantages. The delegating/decentralized firm acquires an advantage (the lower input prices) and a disadvantage (the less aggressive behavior in the downstream market). That is, we provide another plausible scenario leading to an asymmetric managerial structure in oligopoly. That is, external sourcing is the key in our model.

Several papers consider duopoly models with sequential choice of production volumes to obtain asymmetric managerial forms.

Mujumdar and Pal (2007) consider a symmetric duopoly with twice the production opportunities. They show that the first mover delegates to a manager with a profitbased incentive contract, while the second mover delegates with a sales-based contract. The first mover does not have an incentive to change the owner's best response because she/he chooses her/his quantity based on the second mover's best response, although the second mover can benefit from making it more aggressive.

Kopel and Löffler (2008) consider the interaction of two commitment devices: processinnovation R\&D and delegation to a manager in a Stackelberg duopoly model. They 
show that both firms invest in process innovation and that only the follower delegates to a manager because (i) a Stackelberg leader cannot benefit from the strategic delegation and (ii) the leader's cost-reducing investment does not directly affect the follower's quantity choice. They also show that the follower can overcome the disadvantage of its second-mover position.

Kopel and Löffler (2012) consider a duopoly model in which firms can choose their organizational governance and leader-follower roles. They consider the delegation cost and show that a firm chooses to be the market leader and does not delegate, whereas the other firm hires a manager. The key factor in the three papers is sequential choices of quantities.

Recent work by Pan et al. (2020) also shows the possibility that an asymmetric managerial structure emerges in a duopoly with quantity competition. The key factor in their paper is equilibrium multiplicity under the convex inverse demand proposed by Ishibashi and Matsushima (2009). ${ }^{14}$ Under some parameter sets, one of the firms does not delegate to a manager in order to avoid the worse equilibrium. That is, the demand system is the key factor in obtaining an asymmetric managerial structure.

\section{Model}

We consider a Cournot duopoly market with a monopolistic supplier. The inverse demand in the downstream market is

$$
p=a-q_{i}-q_{j}
$$

where $p$ is the price, $a$ is a positive constant, and $q_{i}$ is the quantity supplied by firm $i$ $(i, j=1,2 ; j \neq i)$.

\footnotetext{
${ }^{14}$ Pan $(2018,2020)$ are applications of the demand system in Ishibashi and Matsushima (2009) to the problems of endogenous timing and firm entry, respectively.
} 
Each of the profit-maximizing downstream firms needs three types of inputs produced by the downstream firms and the monopolistic supplier (hereinafter we refer to the latter as "the supplier"). To produce one unit of the final product, each downstream firm uses each one unit of the three inputs, respectively. We assume that the three firms do not incur any production cost in producing their inputs for notational simplicity. The total marginal cost of firm $i, c_{i}(i=1,2)$, is the sum of the input prices imposed by the rival firm and the supplier, $r_{i}$ and $w$, that is, $c_{i}=r_{i}+w$. Here, the supplier offers a common input price $w$ to firms 1 and 2. Figure 1 summarizes the trading structure in the industry.

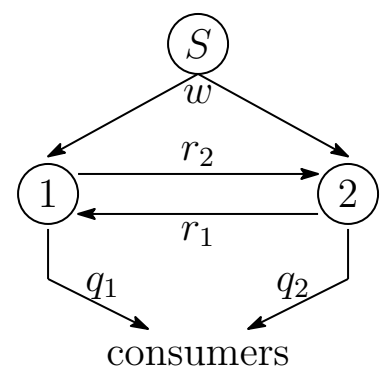

Figure 1: The market structure

The profits of firm $i$ and the supplier, $\Pi_{i}$ and $\Pi_{S}$, are

$$
\begin{aligned}
& \Pi_{i}=\left(R_{i}-\left(r_{i}+w\right) q_{i}\right)+r_{j} q_{j}, \quad \text { where } R_{i}=\left(a-q_{i}-q_{j}\right) q_{i}, \quad(i, j=1,2, j \neq i), \\
& \Pi_{S}=w\left(q_{1}+q_{2}\right) .
\end{aligned}
$$

$\Pi_{i}(i=1,2)$ is the sum of the profits from the downstream and upstream/input markets.

In the duopoly market, each downstream firm (owner) determines whether to delegate the downstream production to its manager. Following the tradition in the context of strategic delegation (Fershtman and Judd, 1987; Basu, 1995), we assume that the managerial compensation contracts are of the form $A_{i}+B_{i} g_{i}$, where $A_{i}$ and $B_{i}$ are a 
fixed wage and a weight on the performance measure $g_{i}$ :

$$
g_{i}=\alpha_{i} \Pi_{i}+\left(1-\alpha_{i}\right) R_{i}
$$

where $\alpha_{i}$ is the weight imposed by the owner of firm $i$. The reservation utilities of the managers are assumed to be zero. ${ }^{15}$ The linear formulation of $g_{i}$ is consistent with the previous studies showing the plausibility of linear contracts (Bhattacharyya and Lafontaine, 1995; Chu and Sappington, 2007; Bose, Pal, and Sappington, 2011).

We mention the plausibility of employing managerial delegation. Bloomfield (2021) finds that Cournot firms are more likely to commit to revenue-based executive pay after the effectuation of the new Compensation Discussion and Analysis (CD\&A) section of the proxy exchanges, which ordered public listing firms on American stock exchanges to furnish more detailed disclosures concerning the compensation plans for their executives. He concludes that the behavioral changes of those public listing firms are consistent with the theoretical prediction by Fershtman and Judd (1987). He also mentions "many firms add revenue-based pay to their CEO's pay packages immediately after adopting the new CD\&A requirements" (Bloomfield, 2021, pp. 620-621). ${ }^{16}$

We consider the following four-stage game: ${ }^{17}$

1. Each downstream firm's owner determines whether to delegate overall downstream production to its manager. If the owner delegates, the firm needs to incur a

15 Several articles explored cases where a manager's compensation is determined by the combination of various parameters (profits and sales quantities (Vickers, 1985), own profits and rival's profits (SalasFumás, 1992; Miller and Pazgal 2002), profits and market share (Ritz, 2008)). In this paper, we use the traditional compensation scheme to highlight the new sources of asymmetric managerial structures.

16 Gipper (2021) shows the changes in incentive pay packages after the revision of CD\&A.

17 The timing structure is different from those in the related papers (e.g., Liao, 2010; Claude, 2018) and suitable for the motivating example in the introduction. Those related papers consider the following sequence: incentive contracts, input prices, and strategic variables in the downstream market. The timing structure in those related papers appears to be plausible in other contexts. We believe that the timing structure in a game-theoretical model should depend on the context that researchers consider. 
fixed cost, $F$, to delegate. This assumption follows Basu (1995). We denote the decisions of delegation and no delegation as $D$ and $N$, respectively.

Firms are often reluctant to change their organizational forms, so-called "organizational inertia," because of routines (e.g., Yi et al., 2016). Changing the forms can be a long-term decision because of such inertia. Therefore, we assume that the firms decide whether to delegate in the first stage.

2. The supplier and the owners of firms 1 and 2 simultaneously determine the linear input prices, $w, r_{2}$, and $r_{1}$. As explained in the introduction, even if we assume that the supplier can offer different input prices for the downstream firms, the qualitative nature of the main results does not change (see Section 5).

The time horizon of the contract terms in input markets is longer than that of the incentive contracts. Manufacturers tend to sign long-term contracts to avoid opportunistic behaviors (e.g., hold-up problems). The signed trading terms tend to be valid for longer periods.

3. Each downstream firm's owner determines the incentive scheme for its manager, $\alpha_{i}$, if it delegates the production in the first stage.

We treat the proposal of an incentive scheme for managers as a yearly based decision, which is shorter than those in the input market.

4. The agents with the right to control the downstream production determine the quantities in the downstream market.

We derive the subgame perfect Nash equilibrium by backward induction. 


\section{Analysis}

We consider three subgames: (i) both firms delegate, case $(D, D)$; (ii) one of the firms delegates, case $(N, D)$; (iii) no firm delegates, case $(N, N)$. Finally, we use the outcomes in the three subgames and obtain the main result.

\subsection{Both firms delegate, case $(D, D)$}

We consider the case in which both firms delegate.

The fourth stage The objective of the manager in firm $i$ is

$$
\begin{aligned}
g_{i} & =\alpha_{i} \Pi_{i}+\left(1-\alpha_{i}\right) R_{i} \\
& =\alpha_{i}\left\{\left(a-q_{i}-q_{j}-r_{i}-w\right) q_{i}+r_{j} q_{j}\right\}+\left(1-\alpha_{i}\right)\left(a-q_{i}-q_{j}\right) q_{i} .
\end{aligned}
$$

In this stage, both firms' managers simultaneously set the quantities. We can obtain the best response function of firm $i$ 's manager as follows:

$$
q_{i}=\frac{a-q_{j}-\alpha_{i}\left(r_{i}+w\right)}{2}, \quad(i, j=1,2, j \neq i) .
$$

This best response function is a decreasing function of $\alpha_{i}$. As $\alpha_{i}$ becomes smaller, in other words, as the manager's attention to the cost $\left(r_{i}+w\right)$ is weaker, the quantity of firm $i$ increases. The best response function does not include the input price imposed by firm $i, r_{j}$, that is, the manager does not take into account the revenue from the input market, as in the standard quantity competition with internal market licensing (e.g., Faulí-Oller and Sandonís, 2002, p.195). ${ }^{18}$ This manager's ignorance regarding the revenue from selling input influences the choice of firm $i$ 's owner on $\alpha_{i}$ in the third

\footnotetext{
${ }^{18}$ Faulí-Oller and Sandonís (2002) discuss the Cournot duopoly with a licenser (firm 1) and a licensee (firm 2). The licenser (firm 1)'s maximization problem $\max _{x_{1}} p_{1}\left(x_{1}, x_{2}\right) x_{1}+r x_{2}$ leads to the first-order condition: $p_{1}+x_{1}\left(\partial p_{1} / \partial x_{1}\right)=0$, where $p_{1}\left(x_{1}, x_{2}\right)$ is the inverse demand for the licenser, $x_{i}$ is the quantity of firm $i(i=1,2)$, and $r$ is the per unit fee on the licensee. This condition does not include $r$, as in our paper. This property is common in the context of licensing under quantity competition.
} 
stage. Solving the simultaneous equations mentioned in (1), we obtain the quantity of firm $i$ :

$$
q_{i}(\boldsymbol{\alpha}, \boldsymbol{r}, w)=\frac{a-2 \alpha_{i}\left(r_{i}+w\right)+\alpha_{j}\left(r_{j}+w\right)}{3} .
$$

When $\alpha_{j}$ is small, manager $i$ knows that the rival firm commits to set a higher $q_{j}$, inducing manager $i$ to set a small output because of the strategic substitution of downstream outputs. Using the result in (2), we have the profit in the fourth stage:

$$
\Pi_{i}(\boldsymbol{\alpha}, \boldsymbol{r}, w)=\left(q_{i}(\boldsymbol{\alpha}, \boldsymbol{r}, w)-\left(1-\alpha_{i}\right)\left(r_{i}+w\right)\right) q_{i}(\boldsymbol{\alpha}, \boldsymbol{r}, w)+r_{j} q_{j}(\boldsymbol{\alpha}, \boldsymbol{r}, w)
$$

The first term is the profit from the downstream market and the second term is the profit from the input market.

The third stage The owner of firm $i$ sets the parameter $\alpha_{i}$ to maximize profit $\Pi_{i}(\boldsymbol{\alpha}, \boldsymbol{r}, w)$. Using (3), we solve the maximization problem and then obtain the owner's best response function:

$$
\alpha_{i}\left(\alpha_{j}, \boldsymbol{r}, w\right)=\frac{6\left(r_{i}+w\right)-a}{4\left(r_{i}+w\right)}-\frac{\alpha_{j}\left(r_{j}+w\right)}{4\left(r_{i}+w\right)}+\frac{3 r_{j}}{4\left(r_{i}+w\right)}, \quad(i, j=1,2, j \neq i) .
$$

The first and second terms in (4) are the standard best response in the delegation game, and the last term in (4) is the element, which reflects firm $i$ 's revenue from the input market.

To maximize profit, firm $i$ must consider the trade-off between the downstream profit and the profit from firm $j$. However, the Cournot best response function (1) shows that the manager of firm $i$ does not consider the revenue in the input market.

In the third stage, each firm can use the degree of delegation $\alpha_{i}$ as a commitment device to decrease the quantity in the fourth stage to balance the profits from the downstream and input markets (Macho-Stadler and Verdier, 1991). ${ }^{19}$ Solving the

\footnotetext{
19 Macho-Stadler and Verdier (1991) also show such delegation incentives to lower quantities in a
} 
simultaneous equations in (4), we obtain $\alpha_{i}(\boldsymbol{r}, w)$

$$
\alpha_{i}(\boldsymbol{r}, w)=\frac{-a+8\left(r_{i}+w\right)-2\left(r_{j}+w\right)}{5\left(r_{i}+w\right)}+\frac{4 r_{j}-r_{i}}{5\left(r_{i}+w\right)}
$$

The first term in (5) captures the degree of delegation in the standard delegation game without the last term in (4), and the second term in (5) captures the impact of their revenues from inputs on $\alpha_{i}$. As explained before, the input revenue makes the firm less aggressive (a high $\alpha_{i}$ ) in the fourth-stage competition.

By substituting (5) into (2), we can rewrite the output as a function of $(\boldsymbol{r}, w)$ :

$$
q_{i}(\boldsymbol{r}, w)=\frac{2\left(a-3\left(r_{i}+w\right)+2\left(r_{j}+w\right)\right)}{5}+\frac{2 r_{i}-3 r_{j}}{5}
$$

The second term in (6) reflects the impact of their revenues from inputs on the quantity through the delegation levels. An increase in its input price, $r_{i}$, leads to a larger quantity because the rival becomes less aggressive by offering a higher $\alpha_{j}$. The converse holds, that is, an increase in its rival's input price, $r_{j}$, induces a smaller quantity.

The second stage The supplier and firms 1 and 2 set $w, r_{2}$, and $r_{1}$ to maximize their own profits. The supplier's profit function is

$$
\Pi_{S}(\boldsymbol{r}, w)=w q_{1}\left((\boldsymbol{r}, w)+q_{2}(\boldsymbol{r}, w)\right) .
$$

Solving the first-order condition, we obtain the best response function of the supplier:

$$
w=\frac{4 a-3\left(r_{i}+r_{j}\right)}{8}
$$

The negative coefficient of $r_{i}$ (resp., $r_{j}$ ) comes from the strategic substitution between the prices of firm $i$ 's (resp. firm $j$ 's) complementary inputs, $w$ and $r_{i}$ (resp., $r_{j}$ ), duopoly market with cross-shareholding. Because of the cross-shareholding by one of the firms, the holding firm weighs heavily on the profit in the delegation stage to mitigate competition (Proposition 1 in their paper). 
which is a key factor for deriving the asymmetric outcome. The strategic substitution resembles that in the standard Cournot complementary input market. Therefore, as $r_{i}$ or $r_{j}$ increases, the monopoly power of the supplier weakens.

Firm $i$ 's profit function is $(i, j=1,2, j \neq i)$ :

$$
\Pi_{i}(\boldsymbol{r}, w)=\left(q_{i}(\boldsymbol{r}, w)-\left(1-\alpha_{i}\right)\left(r_{i}+w\right)\right) q_{i}(\boldsymbol{r}, w)+r_{j} q_{j}(\boldsymbol{r}, w) .
$$

Solving the first-order conditions, we have the best response functions:

$$
\begin{aligned}
r_{j} & =\frac{7\left(a-\left(2 r_{i}+3 w\right)+2 w\right)}{34}+\frac{5\left(2 a+\left(r_{i}+4 w\right)-6 w\right)}{34} \\
& =\frac{17 a-17 w-9 r_{i}}{34}, \quad(i, j=1,2, j \neq i) .
\end{aligned}
$$

The first fraction in the first line comes from the gain from the downstream competition. The marginal gain from weakening the rival through $r_{j}$ is larger as firm $i$ 's efficiency increases. The second fraction in the first line comes from the direct gain from the input market.

Solving the simultaneous equations in (8) and (10) and substituting the derived outcome into (7) and (9), we obtain the proposition:

Proposition 1 If both firms delegate, the equilibrium input prices, output levels, and $\alpha_{i}(i=1,2)$ are

$$
w^{*}=\frac{35 a}{121}, \quad r_{j}^{*}=\frac{34 a}{121}, \quad q_{i}^{*}=\frac{14 a}{121}, \quad \alpha_{i}^{*}=\frac{79}{69} .
$$

The resulting overall profits under $(D, D)$ are

$$
\pi_{i}=\pi_{j}=\frac{812 a^{2}}{14641}-F \simeq 0.0555 a^{2}-F, \quad \pi_{S}=\frac{980 a^{2}}{14641} \simeq 0.0669 a^{2}
$$

To clarify the role of mutual outsourcing, we also solve the simultaneous equations in (10) and $w=0$. Then, we obtain the result: 
Result 1 We hypothetically suppose that the supplier does not have any bargaining power, that is, $w=0$. If both firms delegate, the equilibrium input prices, output levels, and $\alpha_{i}(i=1,2)$ are

$$
w^{*}=0, r_{j}^{*}=\frac{17 a}{43}, q_{i}^{*}=\frac{7 a}{43}, \alpha_{i}^{*}=\frac{22}{17} .
$$

The profits under $(D, D)$ are

$$
\pi_{i}=\pi_{j}=\frac{203 a^{2}}{1849}-F \simeq 0.1098 a^{2}-F, \quad \pi_{S}=0
$$

Note that $\alpha_{i}(i=1,2)$ is strictly larger than 1 in Proposition 1 and Result 1 . Contrary to the standard delegation game in Cournot competition, each owner places weights on its profit rather than its revenue, leading to less aggressive behavior in the downstream market. Proposition 1 and Result 1 clarify that the existence of mutual outsourcing is sufficient to induce less aggressive behavior in the downstream market.

\subsection{Only one firm delegates, case $(N, D)$}

Now suppose that only firm $j$ delegates. Because the mathematical procedures are similar to those in Section 4.1, we directly mention the proposition in this case.

Proposition 2 If only firm $j$ delegates, the equilibrium input prices, output levels, and $\alpha_{i}(i=1,2)$ are

$$
w^{*}=\frac{4 a}{13}, r_{j}^{*}=\frac{3 a}{13}, r_{i}^{*}=\frac{9 a}{26}, q_{i}^{*}=\frac{3 a}{26}, q_{j}^{*}=\frac{3 a}{26}, \alpha_{i}^{*}=1, \alpha_{j}^{*}=\frac{17}{14}
$$

The resulting overall profits under $(N, D)$ are

$$
\pi_{i}=\frac{27 a^{2}}{676} \simeq 0.0399 a^{2}, \pi_{j}=\frac{45 a^{2}}{676}-F \simeq 0.0666 a^{2}-F, \pi_{S}=\frac{12 a^{2}}{169} \simeq 0.0710 a^{2}
$$

We have a remark on the input price $w$. 
Remark 1 The input price $w$ in case $(N, D), w=4 a / 13 \simeq 0.308 a$, is higher than that in case $(D, D), w=35 a / 121 \simeq 0.289 a$.

We explain the intuition behind Remark 1. Firm $i$ without delegation anticipates a lower quantity supplied by firm $j$, which delegates, and sets an input price lower than that in case $(D, D)$. Because of the mechanism of the complementary input pricing, the supplier in case $(N, D)$ sets a higher input price than in case $(D, D)$. The supplier's higher input price implies that abolishing delegation causes a reduction of the actual market size for the downstream firms.

To clarify the role of the strategic interaction in the input market, we also solve the simultaneous equations in (12) and (13) and $w=0$. Then, we obtain the result:

Result 2 We hypothetically suppose that the supplier does not have any bargaining power, that is, $w=0$. If only firm $j$ delegates, the equilibrium input prices, output levels, and $\alpha_{i}(i=1,2)$ are

$$
w^{*}=0, r_{j}^{*}=\frac{a}{3}, r_{i}^{*}=\frac{a}{2}, q_{i}^{*}=\frac{a}{6}, q_{j}^{*}=\frac{a}{6}, \alpha_{i}^{*}=1, \alpha_{j}^{*}=\frac{3}{2} .
$$

The profits under $(N, D)$ are

$$
\pi_{i}=\frac{a^{2}}{12} \simeq 0.0833 a^{2}, \pi_{j}=\frac{5 a^{2}}{36}-F \simeq 0.139 a^{2}-F, \quad \pi_{S}=0
$$

As in Proposition 1 and Result 1, the delegating owner places a negative weight on its revenue in the manager's objective function in Proposition 2 and Result 2. This delegation decision balances the profits from the downstream and input markets.

Firm $j$ 's better procurement condition (the lower $r_{j}$ ) offsets the less aggressive behavior caused by the higher $\alpha_{j}$. Then, the quantities of the two firms are the same. 


\subsection{No firm delegates, case $(N, N)$}

Next, we consider the case in which no firm delegates to managers, that is, $\alpha_{i}=\alpha_{j}=1$. As in the previous subsection, because the mathematical procedures are similar to those in Section 4.1, we directly mention the proposition in this case:

Proposition 3 If no firm delegates, the equilibrium input prices and output levels $(i=$ $1,2)$ are

$$
w^{*}=\frac{6 a}{17}, \quad r_{j}^{*}=\frac{5 a}{17}, \quad q_{i}^{*}=\frac{2 a}{17} .
$$

The resulting profits under $(N, N)$ are

$$
\pi_{i}=\pi_{j}=\frac{14 a^{2}}{289} \simeq 0.0484 a^{2}, \quad \pi_{S}=\frac{24 a^{2}}{289} \simeq 0.0830 a^{2} .
$$

We have a remark on the supplier's input price $w$.

Remark 2 Similar to Remark 1, the supplier's input price in case $(N, N), w=6 a / 17 \simeq$ $0.353 a$, is higher than that in case $(N, D), w=4 a / 13 \simeq 0.308 a$. The incremental amount of the supplier's input price in Remark 2, 0.045a, is significantly higher than that in Remark 1, 0.018a.

The quantities in case $(N, N)$ are larger than those in case $(D, D)$. The increase in downstream competition through no delegation dominates the supplier's monopoly power in response to the reduction of $r_{i}(i, j=1,2, j \neq i)$.

To clarify the role of the strategic interaction in the input market, we also solve the simultaneous equations in (16) and $w=0$. Then, we obtain the result:

Result 3 We hypothetically suppose that the supplier does not have any bargaining power, that is, $w=0$. If no firm delegates, the equilibrium input prices, output levels, and $\alpha_{i}(i=1,2)$ are

$$
w^{*}=0, r_{j}^{*}=\frac{5 a}{11}, q_{i}^{*}=\frac{2 a}{11}
$$


The profits under $(N, N)$ are

$$
\pi_{i}=\pi_{j}=\frac{14 a^{2}}{121} \simeq 0.1157 a^{2}, \quad \pi_{S}=0 .
$$

The quantities in Result 3 are the largest among the three hypothetical cases.

\subsection{The first stage}

From Sections 4.1, 4.2, and 4.3, we obtain the payoff matrix in the first stage (see Table 1). Using the outcomes, we obtain Proposition 4.

\begin{tabular}{|l|lr|ll|}
\hline $1 / 2$ & \multicolumn{2}{|c|}{$D$} & \multicolumn{2}{|c|}{$N$} \\
\hline$D$ & \multicolumn{2}{|r|}{$0.0555 a^{2}-F$} & \multicolumn{2}{|c}{$0.0399 a^{2}$} \\
& \multicolumn{2}{|r|}{$0.0555 a^{2}-F$} & & $0.0666 a^{2}-F$ \\
\hline$N$ & \multicolumn{2}{|r}{$0.0666 a^{2}-F$} & \multicolumn{2}{|c}{$0.0484 a^{2}$} \\
& $0.0399 a^{2}$ & & $0.0484 a^{2}$ & \\
\hline
\end{tabular}

$D$ : Delegation; $N$ : No delegation.

Table 1: The first-stage decision

Proposition 4 The profits under $(D, D)$ are higher than those under $(N, N)$ if $F<$ $0.0071 a^{2}$.

As we check in Remarks 1 and 2, the larger the number of delegating firms, the lower the supplier's input price. Furthermore, as we show in Propositions 1 and 2, employing delegation induces the firm to be less aggressive than an owner-managed firm, which mitigates downstream competition. From the two effects, the profits under $(D, D)$ can be higher than those under $(N, N)$. Proposition 4 implies that mutual outsourcing can facilitate collusive conduct. ${ }^{20}$ We discuss the welfare properties of the subgames in Section 4.5.

20 Of course, mutual outsourcing saves fixed costs to produce additional complementary inputs, although such costs are beyond the scope of this paper. 
The profit ranking in Proposition 4 is not common but resembles those in Liao (2010) and Meccheri and Fanti (2014) whose mechanisms differ from ours. ${ }^{21}$

From the payoff matrix, we obtain the following proposition:

Proposition 5 Both owners delegate if and only if $F \leq 0.0156 a^{2}$; Only one of the owners delegates if and only if $0.0156 a^{2} \leq F \leq 0.0182 a^{2} ;$ No owner delegates if and only if $0.0182 a^{2} \leq F$.

In the symmetric downstream duopoly, there is a possibility that asymmetry of the delegation decisions occurs. In many previous related papers, decisions on strategic delegation are strategic complements, that is, the outcomes of $(D, D)$ and $(N, N)$ can coexist (e.g., Colombo and Scrimitore, 2018), which is in contrast to Proposition 5.

Here, we explain the mechanism behind Proposition 5. First, if delegation is costless, both firms employ delegation. Setting the costless situation as a starting point, as the fixed cost for delegation $F$ increases, delegation becomes less profitable. One of the firms stops employing delegation at the threshold value of $F\left(F=0.0156 a^{2}\right)$. At the fixed delegation cost slightly higher than the threshold value of $F, F=0.0156 a^{2}$, the rival downstream firm does not change its managerial form, anticipating the substantial increase of the supplier's input price (Remark 2). The substantial increase comes from the strategic interaction in the input market. Therefore, when $F$ is moderate, the asymmetric managerial forms occur in equilibrium.

Proposition 5 implies that mimicking the well-performed rival's organizational form can be an inconsiderate decision. Actually, Samsung is more likely to employ centralized management (Joseph et al., 2016), and Google is more likely to employ delegated management (Steiber, 2014). Following Proposition 5, we can conclude that the co-existence

\footnotetext{
${ }^{21}$ Bhattacharjee and Pal (2014) show a similar result in a duopoly model with network externalities.
} 


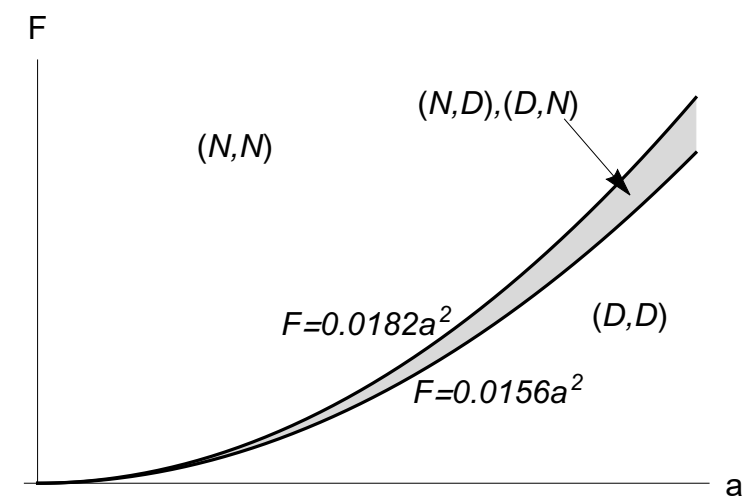

Figure 2: The parameter range in Proposition 5

of asymmetric managerial forms is a considerable consequence.

Finally, we restate the logic behind the asymmetric outcome in Vroom (2006) and compare it with ours. In his asymmetric outcome, the decentralized firm acquires an advantage from aggressiveness in the downstream market and the disadvantage of the double mark-up problem. We provide a different source to balance the two firms' competitive advantages. The delegating/decentralized firm acquires the advantage of the lower input price and the disadvantage of less aggressive behavior in the downstream market.

\subsection{Welfare analysis}

We briefly check the welfare ranking between the three cases.

The consumer surplus in our model with the linear demand is $\left(q_{1}+q_{2}\right)^{2} / 2$. That is, the consumer surplus monotonically increases in the total quantity supplied by the downstream firms. From Propositions 1, 2, and 3, we find that the total quantity in Proposition 3 is the highest and that in Proposition 2 is the lowest.

Furthermore, the total surplus in our model is the sum of the firms' profits and the consumer surplus. From the assumption that no firm incurs production costs except for input prices, the total surplus minus the delegation costs monotonically increases 
in the total quantity supplied by the downstream firms. In addition to this argument, a delegating firm incurs the fixed cost $F$. The total delegation cost in the case of Proposition 3 is the lowest (no delegation cost), and that in the case of Proposition 1 is the highest (two delegations). From the discussions, we have the following proposition:

Proposition 6 The consumer surplus in case $(N, N)$ is the highest and that in case $(N, D)$ is the lowest. The total surplus in case $(N, N)$ is the highest. The total surplus in case $(D, D)$ is the lowest if $F>2419 a^{2} / 4948658 \simeq 4.889 \times 10^{-4}$; otherwise, that in case $(N, D)$ is the lowest.

\section{$5 \quad$ Remarks}

We have incorporated the two key elements in the smartphone industry: the supplier and the mutual outsourcing. Below, first, we derive the two results with only one of the two elements in the model, respectively, to clarify that the existence of multiple inputs is essential for obtaining the asymmetric organizational forms. Second, we show that input price discrimination by the supplier does not bear on the main result (Proposition 5). The detail is available upon request.

Without mutual outsourcing We remove mutual outsourcing from the main model. In other words, we consider the case in which $r_{j}=r_{i}=0$.

We can show that the profits under $(N, N)$ are higher than those under $(D, D)$, as in the standard delegation game with quantity competition, in contrast to Proposition 4. Furthermore, the supplier offers the same input price $w=a / 2$ regardless of the managerial structures, which is in contrast to the propositions in Section 4.

The parameters of the incentive contracts in the two cases, (i) one delegation by firm 2 and (ii) two delegations, are $\alpha_{2}=3 / 4$ and $\alpha_{i}=4 / 5(i=1,2)$, respectively. The 
equilibrium weights in the delegation cases also differ from those in the outcomes in Section 4.

In this case, an asymmetric organizational structure does not appear as an equilibrium outcome.

Without the supplier We remove the supplier from the main model. In other words, we consider the case where $w=0$.

We can show that the profits under $(N, N)$ are higher than those under $(D, D)$ in contrast to Proposition 4. From the two scenarios, we find that the two key elements are necessary for obtaining Proposition 4 in which the profits under $(D, D)$ are higher than those under $(N, N)$.

The parameters of the incentive contracts in the two cases, (i) one delegation by firm 2 and (ii) two delegations, are $\alpha_{2}=3 / 2$ and $\alpha_{i}=22 / 17(i=1,2)$, respectively. The equilibrium weights in the delegation cases are similar to those in the outcomes in Section 4.

In this case, an asymmetric organizational structure does not appear as an equilibrium outcome. From the two scenarios, the two key elements in our model are necessary for obtaining the asymmetric outcome in Proposition 5.

Different input prices by the supplier This part is the robustness check of the main model. Now, we suppose that the supplier can price discriminate to the downstream firms, that is, $w_{i}$ and $w_{j}$ can be different.

We can show that the profits under $(D, D)$ are higher than those under $(N, N)$, as in Proposition 4.

The parameters of the incentive contracts in the two cases, (i) one delegation by firm 2 and (ii) two delegations, are $\alpha_{2}=19 / 16$ and $\alpha_{i}=79 / 69(i=1,2)$, respectively. 
The equilibrium weights in the delegation cases are similar to those in the outcomes in Section 4.

In this case, an asymmetric organizational structure appears as an equilibrium outcome when $F$ is moderate, as in Proposition 4.

\section{Conclusion}

We consider a downstream duopoly model with a monopolistic common supplier and mutual outsourcing between the two downstream firms. The recent procurement environment in the smartphone industry motivates us to formulate the market structure. We also incorporate managerial delegations into the duopoly model, as in Fershtman and Judd (1987), because deciding on organizational forms within a firm is critical to achieving better performance in almost all industries (Foss and Klein, 2014).

Section 4 shows that depending on the fixed cost of delegating to a manager, we obtain three types of managerial forms in equilibrium: (i) both owners delegate if and only if the fixed cost is low; (ii) only one of the owners delegates if and only if the fixed cost is medium; (iii) no owner delegates if and only if the fixed cost is high. Section 5 shows that the two key elements in our model are necessary for obtaining the asymmetric managerial forms in the main results.

Following the literature of strategic delegation, we assume the standard linear combination of profit and revenue as an incentive contract to a manager. The linear formulation is consistent with the previous studies finding the plausibility of linear contracts (Bhattacharyya and Lafontaine, 1995; Chu and Sappington, 2007; Bose, Pal, and Sappington, 2011). Contrary to the formulation, recently, Fanti et al. (2017) and Dickson

et al. (2021) propose interesting incentive structures. They show nonstandard effects of the incentive structure. 
We briefly discuss nonlinear incentive contracts in our main model, as in Dickson et al. (2021). Following their formulation, we set the nonlinear performance measure as follows: $g_{i}=\alpha_{i} \Pi_{i}+\left(1-\alpha_{i}\right) v\left(R_{i}\right)$, where $v\left(R_{i}\right)$ is a concave function of the revenue $R_{i}$. Incorporating the concave function differs from the performance measure in the main model. Because of the concavity, each firm is less aggressive than when $v\left(R_{i}\right)$ is linear in $R_{i}, v\left(R_{i}\right)=R_{i}$. Even in this modified formulation, each firm needs to internalize the licensing revenue by offering an incentive contract that makes its manager less aggressive. We guess that each delegating firm sets $\alpha_{i}$ to be greater than 1 unless the concavity of $v\left(R_{i}\right)$ is strong. If this logic holds, the relationship between the decisions to employ delegation and the supplier's monopoly power remains in the modified formulation. Therefore, we guess that the main results hold even in the modified formulation. However, because the modified model requires us to solve complex problems, we leave these problems to future research.

Besides, it may be interesting to investigate oligopoly competition with nonprofit maximizing firms in our model framework (for instance, socially concerned firms (e.g., Kopel and Putz, 2021, and the references therein)). This possibility is also left for future research. Furthermore, considering the endogenous choice of outsourcing in our model framework is an interesting topic (e.g., Colombo and Scrimitore, 2018) for future research.

\section{Appendix}

\section{The stage games in Section 4.2}

Suppose that only firm $j$ delegates. We can use the derived outcome on the quantities in the fourth stage in the previous subsection. Thus, first, we consider the third stage. 
The third stage In this subgame, firm $i$ does not delegate; in other words, firm $i$ sets $\alpha_{i}=1$ in this stage. From (4), we can obtain $\alpha_{j}(1, \boldsymbol{r}, w)$ as

$$
\alpha_{j}=(1, \boldsymbol{r}, w)=\frac{-a+6\left(r_{j}+w\right)-\left(r_{i}+w\right)}{4\left(r_{j}+w\right)}+\frac{3 r_{i}}{4\left(r_{j}+w\right)} .
$$

By using this equation and (2), we can rewrite the outputs as a function of $(\boldsymbol{r}, w)$ :

$$
\begin{aligned}
& q_{i}(\boldsymbol{r}, w)=\frac{a+2\left(r_{j}+w\right)-3\left(r_{i}+w\right)}{4}+\frac{r_{i}}{4}, \\
& q_{j}(\boldsymbol{r}, w)=\frac{a+\left(r_{i}+w\right)-2\left(r_{j}+w\right)}{2}-\frac{r_{i}}{2} .
\end{aligned}
$$

The second stage Using the quantities derived immediately prior to equation (7), we can obtain the supplier's best response function as:

$$
w=\frac{3 a-2\left(r_{i}+r_{j}\right)}{6}
$$

The best response functions of the downstream firms are:

$$
\begin{aligned}
& r_{j}=\frac{a-\left(2 r_{i}+3 w\right)+2 w}{6}+\frac{2(a+w-2 w)}{6}=\frac{3 a-3 w-2 r_{i}}{6}, \\
& r_{i}=\frac{a-2\left(r_{j}+w\right)+w}{4}+\frac{a+2 r_{j}-3 w}{4}=\frac{a-w}{2} .
\end{aligned}
$$

Solving the simultaneous equations in (11), (12), and (13), we obtain Proposition 2.

\section{The stage games in Section 4.3}

We consider the case in which no firm delegates to managers, that is, $\alpha_{i}=\alpha_{j}=1$.

The fourth stage From equation (2), the equilibrium output of firm $i$ is equal to

$$
q_{i}(\boldsymbol{r}, w)=\frac{a+\left(r_{j}+w\right)-2\left(r_{i}+w\right)}{3}
$$


The second stage Anticipating the quantities in (14), the supplier maximizes the profit in (7). Solving the first-order conditions of the maximization problem, the supplier's best response function is:

$$
w=\frac{2 a-r_{j}-r_{i}}{4}, \quad(i, j=1,2, j \neq i)
$$

Anticipating the quantities in (14), each downstream firm maximizes the profit in (9). Solving the first-order condition of the maximization problems, we obtain the best response function of each downstream firm:

$$
r_{j}=\frac{5 a-5 w-r_{i}}{10}, \quad(i, j=1,2, j \neq i)
$$

Using the best response functions in (15) and (16), we can obtain Proposition 3.

\section{References}

Ai, Youqiong; Lu, Thomas Y., 2019. On the rationality of bundled rebate program in modem chip industry: An analysis on Qualcomm's case. Journal of Industry, Competition and Trade 19(4), 641-660.

Basu, Kaushik, 1995. Stackelberg Equilibrium in Oligopoly: An Explanation Based on Managerial Incentives. Economics Letters, 49(4), 459-464.

Bhattacharjee, Trishita; Pal, Rupayan, 2014. Network externalities and strategic managerial delegation in Cournot duopoly: Is there a prisoners' dilemma? Review of Network Economics, 12(4), 343-353.

Bhattacharyya, Sugato; Lafontaine, Francine, 1995. Double-sided moral hazard and the nature of share contracts. RAND Journal of Economics, 26(4), 761-781. 
Bloomfield, Matthew J., 2021. Compensation disclosures and strategic commitment: Evidence from revenue-based pay. Journal of Financial Economic, 141(2), 620643.

Bolandifar, Ehsan; Kouvelis, Panos; Zhang, Fuqiang, 2016. Delegation vs. control in supply chain procurement under competition. Production and Operations Management, 25(9), 1528-1541.

Bose, Arup; Pal, Debashis; Sappington, David E.M., 2011. On the performance of linear contracts. Journal of Economics \& Management Strategy, 20(1), 159-193.

Carroll, Gabriel, 2015. Robustness and linear contracts. American Economic Review, 105(2), 536-563.

Chatterjee, Ishita; Saha, Bibhas, 2017. Bilateral delegation in duopoly wage and employment bargaining. Managerial and Decision Economics, 38(4), 607-621.

Choi, Kangsik; Lee, Ki-Dong; Lim, Seonyoung, 2020. Managerial Delegation of Competing Vertical Chains with Vertical Externality. B.E. Journal of Theoretical Economics, 20(2), 20190029. https://doi.org/10.1515/bejte-2019-0029.

Chu, Leon Yang; Sappington, David E.M., 2007. Simple cost-sharing contracts. American Economic Review, 97(1), 419-428.

Claude, Denis, 2018. A reconsideration of the link between vertical externality and managerial incentives. Managerial and Decision Economics, 39(5), 526-534.

Colombo, Massimo G.; Delmastro, Marco; Rabbiosi, Larissa, 2007. "High performance" work practices, decentralization, and profitability: Evidence from panel data. Industrial and Corporate Change, 16(6), 1037-1067. 
Colombo, Stefano; Scrimitore, Marcella, 2018. Managerial delegation under capacity commitment: A tale of two sources. Journal of Economic Behavior \& Organization, 150, 149-161.

Dickson, Alex; Mackenzie, Ian A.; Sekeris, Petros G., 2021. Non-linear revenue evaluation in oligopoly. Scotish Journal of Political Economy, Forthcoming. https://doi.org/10.1111/sjpe.12303

Fanti, Luciano; Gori, Luca; Sodini, Mauro, 2017. Managerial Delegation Theory Revisited. Managerial and Decision Economics, 38(4), 490-512.

Fanti, Luciano; Meccheri, Nicola. 2013. Managerial delegation under alternative unionization structures. Labour, 27(1), 38-57.

Fanti, Luciano; Scrimitore, Marcella, 2019. How to compete? Cournot versus Bertrand in a vertical structure with an integrated input supplier. Southern Economic Journal, 85(3), 796-820.

Faulí-Oller, Ramon; Sandonís, Joel, 2002. Welfare reducing licensing. Games and Economic Behavior, 41(2), 192-205.

Fershtman, Chaim; Judd, Kenneth L., 1987. Equilibrium incentives in oligopoly. American Economic Review, 77(5), 927-940.

Foss, Nicolai J.; Klein, Peter G., 2014. Why managers still matter. MIT Sloan Management Review, 56(1), 73-80.

Foss, Nicolai J.; Laursen, Keld; Pedersen, Torben, 2011. Linking customer interaction and innovation: the mediating role of new organizational practices. Organization Science, 22(4), 980-999. 
Foss, Nicolai J.; Lyngsie, Jacob; Zahra, Shaker A., 2013. The role of external knowledge sources and organizational design in the process of opportunity exploitation. Strategic Management Journal, 34(12), 1453-1471.

Gipper, Brandon, 2021. The economic effects of expanded compensation disclosures. Journal of Accounting and Economics, 71(1), 101338.

Habiger, Peter; Kopel, Michael, 2020. Strategic delegation in successive oligopoly with differentiated firms. Economics Letters 194, 109357.

Hoernig, Steffen, 2012. Strategic delegation under price competition and network effects. Economics Letters, 117(2), 487-489.

Hovenkamp, Erik, 2017. Tying, exclusivity, and standard-essential patents. Columbia Science and Technology Law Review 19(1), 79-135.

Hovenkamp, Erik; Simcoe, Timothy, 2020. Tying and Exclusion in FRAND Licensing: Evaluating Qualcomm. Antitrust Source, 19(4), 1-9.

Ishibashi, Ikuo; Matsushima, Noriaki, 2009. The existence of low-end firms may help high-end firms. Marketing Science, 20(1), 136-147.

Joseph, John; Klingebiel, Ronald; Wilson, Alex James, 2016. Organizational structure and performance feedback: Centralization, aspirations, and termination decisions. Organization Science, 27(5), 1065-1083.

Kopel, Michael, Löffler, Clemens, 2008. Commitment,first-mover-,and second-mover advantage. Journal of Economics, 94(2), 143-166.

Kopel, Michael, Löffler, Clemens, 2012. Organizational governance, leadership, and the influence of competition. Journal of Institutional and Theoretical Economics, 
168(3), 362-392.

Kopel, Michael, Pezzino, Mario, 2018. Strategic delegation in oligopoly. Luis C. Corchón and Marco A. Marini (eds.), Handbook of Game Theory and Industrial Organization, Volume II Applications, Chapter 10, 248-285. Massachusetts: Edward Elgar Publishing.

Kopel, Michael; Putz, Eva Maria, 2021. Why socially concerned firms use low-powered managerial incentives: A complementary explanation. Economic Modelling, 94, $473-482$.

Lambertiti, Luca, 2017. An Economic Theory of Managerial Firms: Strategic Delegation in Oligopoly. Routledge: Abingdon, Oxon, UK.

Lee, Dong-Joon; Choi, Kangsik, 2018. The efficiency of competing vertical chains with network externalities. Economics Letters, 168, 1-5.

Leswing, Kif, 2019. Every high-end Android phone will support 5G next year, Qualcomm says. CNBC https://www.cnbc.com/2019/12/04/qualcomm-announces-snapdragon-865-and-765chipset-for-android-phones.html

Liao, Pei-Cheng, 2010. Discriminatory input pricing and strategic delegation. Managerial and Decision Economics, 31(4), 263-276.

Liao, Pei-Cheng, 2014. Strategic delegation of multiple tasks. Australian Economic Papers, 53(1-2), 77-96.

Meccheri, Nicola; Fanti, Luciano. 2014. Managerial delegation contracts under centralized unionization. Managerial and Decision Economics, 35(1), 51-66. 
Macho-Stadler, Inés; Matsushima, Noriaki; Shinohara, Ryusuke, 2021. Organizational structure and technological investment. Journal of Industrial Economics, forthcoming. http://dx.doi.org/10.1111/joie.12277

Macho-Stadler, Inés; Verdier, Thierry, 1991. Strategic managerial incentives and cross ownership structure: A Note. Journal of Economics (Zeitschrift für Nationalökonomie), 53(3), 285-297.

Mosakowski, Elaine, 1998. Entrepreneurial resources, organizational choices, and competitive outcomes. Organization Science, 9(6), 625-643.

Miller, Nolan; Pazgal, Amit, 2002. Relative performance as a strategic commitment mechanism. Managerial and Decision Economics, 23(2), 51-68.

Milliou, Chrysovalantou; Serfes, Konstantinos, 2020. Supplier encroachment with complementary inputs. (September 5, 2020)

Available at SSRN: http://dx.doi.org/10.2139/ssrn.3686437

Mujumdar, Sudesh; Pal, Debashis, 2007. Strategic managerial incentives in a twoperiod Cournot duopoly. Games and Economic Behavior, 58(2), 338-353.

Pan, Cong, 2018. Firms' timing of production with heterogeneous consumers. Canadian Journal of Economics, 51(4), 1339-1362.

Pan, Cong, 2020. Competition between branded and nonbranded firms and its impact on welfare. Southern Economic Journal, 87(2), 647-665.

Pan, Cong; Lee, Dong-Joon; Choi, Kangsik, 2020. Firms' strategic delegation with heterogeneous consumers. Journal of Economics, 131(3), 199-221. 
Plehn-Dujowich, Jose M.; Serfes, Konstantinos, 2010. Product market competition and the taxonomy of managerial compensation. Mimeo.

Pun, Hubert, 2015. The more the better? Optimal degree of supply-chain cooperation between competitors. Journal of the Operational Research Society, 66(12), 20922101.

Ritz, Robert A., 2007. Strategic incentives for market share. International Journal of Industrial Organization, 26(2), 586-597.

Salas-Fumás, Vicente, 1992. Relative performance evaluation of management: The effects on industrial competition and risk sharing. International Journal of Industrial Organization, 10(3), 473-489.

Sengul, Metin; Gimeno, Javier; Dial, Jay, 2012. Strategic delegation: A review, theoretical integration, and research agenda. Journal of Management. 38(1), 375-414.

Sklivas, Steven D., 1987. The strategic choice of managerial incentives. RAND Journal of Economics. 18(3), 452-458.

Sohn, Jiyoung, 2021. Chip shortage reaches smartphone makers. Wall Street Journal. July 19, 2021.

https://www.wsj.com/articles/chip-shortage-reaches-smartphone-makers-11626695523

Srivastava, Shobhit, 2016. MediaTek enters Samsung's supply chain. Counterpoint Research.

https://www.counterpointresearch.com/mediatek-enters-samsungs-supply-chain/

Steiber, Annika, 2014. The Google Model: Managing Continuous Innovation in a Rapidly Changing World. Springer, Cham Heidelberg. 
Sundaram, Anant; John, Teresa A.; John, Kose, 1996. An empirical analysis of strategic competition and firm values: The case of $R \& D$ competition. Journal of Financial Economics, 40(3), 459-486.

Szymanski, Stefan, 1994. Strategic delegation with endogenous costs: A duopoly with wage bargaining. International Journal of Industrial Organization, 12(1), 105116.

Vickers, John, 1985. Delegation and the theory of the firm. Economic Journal, 95, $138-147$.

Vroom, Govert, 2006. Organizational design and the intensity of rivalry. Management Science, 52(11), 1689-1702.

Yi, Sangyoon; Knudsen, Thorbjørn; Becker, Markus C., 2016. Inertia in routines: A hidden source of organizational variation. Organization Science, 27(3), 782-800. 


\section{The impacts of suppliers and mutual outsourcing on organizational forms}

Yasuhiro Arai and Noriaki Matsushima

\section{Supplementary Appendix}

We explain the mathematical procedures to derive the results in Section 5.

\section{A Without mutual outsourcing}

We remove mutual outsourcing from the model. In other words, we consider the case in which $r_{j}=r_{i}=0$.

\section{A.1 Both firms delegate}

The objective of the manager in firm $i$ is

$$
\begin{aligned}
g_{i} & =\alpha_{i} \Pi_{i}+\left(1-\alpha_{i}\right) R_{i} \\
& =\alpha_{i}\left\{\left(a-q_{i}-q_{j}-w\right) q_{i}\right\}+\left(1-\alpha_{i}\right)\left(a-q_{i}-q_{j}\right) q_{i}
\end{aligned}
$$

We can obtain the best response function of firm $i$ 's manager as follows:

$$
q_{i}=\frac{a-q_{j}-\alpha_{i} w}{2}, \quad(i, j=1,2, j \neq i)
$$

Solving the simultaneous equations mentioned above, we obtain the quantity of firm $i$ :

$$
q_{i}(\boldsymbol{\alpha}, w)=\frac{a-2 \alpha_{i} w+\alpha_{j} w}{3}
$$

The third stage The owner of downstream firm $i$ sets the parameter $\alpha_{i}$ to maximize profit $\Pi_{i}(\boldsymbol{\alpha}, w)$. We solve the maximization problem and then obtain the owner's best response function: 


$$
\alpha_{i}\left(\alpha_{j}, w\right)=\frac{6 w-a}{4 w}-\frac{\alpha_{j} w}{4 w} \quad(i, j=1,2, j \neq i)
$$

Solving the simultaneous equations, we obtain $\alpha_{i}(w)$

$$
\alpha_{i}(\boldsymbol{w})=\frac{-a+8 w-2 w}{5 w} .
$$

We can rewrite output as a function of $w$ :

$$
q_{i}(w)=\frac{2(a-3 w+2 w)}{5}
$$

The second stage The supplier sets $w$ to maximize its own profits. From the supplier's profit function, we obtain the equilibrium parameters:

$$
w^{*}=\frac{a}{2}, r_{j}^{*}=0, q_{i}^{*}=\frac{a}{5}, \alpha_{i}^{*}=\frac{4}{5}
$$

The profits under $(D, D)$ are

$$
\pi_{i}=\pi_{j}=\frac{a^{2}}{50}-F, \quad \pi_{S}=\frac{a^{2}}{5}
$$

\section{A.2 Only one firm delegates}

Now suppose that only firm $j$ delegates. Thus, first, we consider the third stage.

The third stage In this subgame, firm $i$ does not delegate; in other words, firm $i$ sets $\alpha_{i}=1$ in this stage. We can obtain $\alpha_{j}(1, w)$ as

$$
\alpha_{j}=(1, w)=\frac{-a+6 w-w}{4 w} .
$$

By using this equation, we can rewrite the outputs as a function of $w$ :

$$
q_{i}(w)=\frac{a+2 w-3 w}{4}, q_{j}(w)=\frac{a+w-2 w}{2} .
$$


The second stage Solving the first-order condition of the supplier, we obtain

$$
w^{*}=\frac{a}{2}, r_{j}^{*}=r_{i}^{*}=0, q_{i}^{*}=\frac{a}{8}, q_{j}^{*}=\frac{a}{4}, \alpha_{i}^{*}=1, \alpha_{j}^{*}=\frac{3}{4} .
$$

The profits under $(N, D)$ are

$$
\pi_{i}=\frac{a^{2}}{64}, \pi_{j}=\frac{a^{2}}{32}-F, \quad \pi_{S}=\frac{3 a^{2}}{16} .
$$

\section{A.3 No firm delegates}

Next, we consider the case in which no firm delegates to managers, that is, $\alpha_{i}=\alpha_{j}=1$.

The fourth stage The quantity of firm $i$ is equal to

$$
q_{i}(w)=\frac{a+w-2 w}{3} .
$$

The second stage Anticipating the quantities, the supplier maximizes its profit. Solving the first-order conditions of the maximization problem, we can obtain the equilibrium outcome under the case in which no firm delegates as follows.

$$
w^{*}=\frac{a}{2}, r_{j}^{*}=0, q_{i}^{*}=\frac{a}{6} .
$$

The profits under $(N, N)$ are

$$
\pi_{i}=\pi_{j}=\frac{a^{2}}{36}, \quad \pi_{S}=\frac{a^{2}}{6}
$$

\section{A.4 First stage}

We can derive the payoff matrix in the first stage (see Table 2).

The equilibrium organizational forms are as follows: The outcome that both owners delegate is sustainable in equilibrium if and only if $F \leq 7 a^{2} / 1600$. The outcome that 


\begin{tabular}{|c|c|c|}
\hline $1 / 2$ & $D$ & $N$ \\
\hline \multirow{2}{*}{$D$} & $a^{2} / 50-F$ & $a^{2} / 64$ \\
\hline & $a^{2} / 50-F$ & $a^{2} / 32-F$ \\
\hline \multirow{2}{*}{$N$} & $a^{2} / 32-F$ & $a^{2} / 36$ \\
\hline & $a^{2} / 64$ & $a^{2} / 36$ \\
\hline
\end{tabular}

$D$ : Delegation; $N$ : No delegation.

Table 2: The first-stage decision: without mutual outsourcing

no owner delegates is sustainable in equilibrium if and only if $a^{2} / 288 \leq F$. The two outcomes can be simultaneously sustainable in equilibrium if and only if $a^{2} / 288 \leq F \leq$ $7 a^{2} / 1600$.

\section{B Without the monopolistic supplier}

We remove the monopolistic supplier from the main model. In other words, we consider the case in which $w_{i}=w_{j}=0$.

\section{B.1 Both firms delegate}

The fourth stage The objective of the manager in firm $i$ is

$$
\begin{aligned}
g_{i} & =\alpha_{i} \Pi_{i}+\left(1-\alpha_{i}\right) R_{i} \\
& =\alpha_{i}\left\{\left(a-q_{i}-q_{j}-r_{i}\right) q_{i}+r_{j} q_{j}\right\}+\left(1-\alpha_{i}\right)\left(a-q_{i}-q_{j}\right) q_{i}
\end{aligned}
$$

We can obtain the best response function of firm $i$ 's manager as follows:

$$
q_{i}=\frac{a-q_{j}-\alpha_{i} r_{i}}{2}, \quad(i, j=1,2, j \neq i) .
$$

Solving the simultaneous equations, we obtain the quantity of firm $i$ :

$$
q_{i}(\boldsymbol{\alpha}, \boldsymbol{r})=\frac{a-2 \alpha_{i} r_{i}+\alpha_{j} r_{j}}{3} .
$$

Using $q_{i}(\boldsymbol{\alpha}, \boldsymbol{r})$, we can obtain the profit in the fourth stage. 
The third stage The owner of downstream firm $i$ sets the parameter $\alpha_{i}$ to maximize its profit. From the profit in the fourth stage, we solve the maximization problem and then obtain the owner's best response function:

$$
\alpha_{i}\left(\alpha_{j}, \boldsymbol{r}\right)=\frac{6 r_{i}-a}{4 r_{i}}-\frac{\alpha_{j} r_{j}}{4 r_{i}}+\frac{3 r_{j}}{4 r_{i}}, \quad(i, j=1,2, j \neq i) .
$$

Solving the simultaneous equations above, we obtain $\alpha_{i}(\boldsymbol{r})$

$$
\alpha_{i}(\boldsymbol{r})=\frac{-a+7 r_{i}+2 r_{j}}{5 r_{i}}
$$

By using $\alpha_{i}(\boldsymbol{r})$, we can rewrite the output as a function of $r$ :

$$
q_{i}(\boldsymbol{r})=\frac{2 a-4 r_{i}+r_{j}}{5}
$$

The second stage Firms 1 and 2 set $r_{2}$, and $r_{1}$ to maximize their own profits. Solving the first-order conditions, we have the best response functions:

$$
r_{j}=\frac{17 a-9 r_{i}}{34}, \quad(i, j=1,2, j \neq i)
$$

From the best response functions, the equilibrium wholesale prices, output levels, and $\alpha_{i}(i=1,2)$ are

$$
w_{i}^{*}=w_{j}^{*}=0, r_{j}^{*}=\frac{17 a}{43}, q_{i}^{*}=\frac{7 a}{43}, \alpha_{i}^{*}=\frac{22}{17} .
$$

The profits under $(D, D)$ are

$$
\pi_{i}=\pi_{j}=\frac{203 a^{2}}{1849}-F \simeq 0.1098 a^{2}-F, \quad \pi_{S}=0 .
$$

\section{B.2 Only one firm delegates}

Now suppose that only firm $j$ delegates. We can use the derived outcome on the quantities in the fourth stage in the previous subsection. Thus, first, we consider the third stage. 
The third stage In this subgame, firm $i$ does not delegate; in other words, firm $i$ sets $\alpha_{i}=1$ in this stage. We can obtain $\alpha_{j}(1, \boldsymbol{r})$ as

$$
\alpha_{j}=(1, \boldsymbol{r})=\frac{-a+6 r_{j}-r_{i}}{4 r_{j}}+\frac{3 r_{i}}{4 r_{j}} .
$$

We can rewrite the outputs as a function of $r$ :

$$
q_{i}(\boldsymbol{r})=\frac{a+2 r_{j}-2 r_{i}}{4}, q_{j}(\boldsymbol{r})=\frac{a-2 r_{j}}{2}
$$

The second stage The best response functions of the downstream firms are:

$$
r_{j}=\frac{3 a-2 r_{i}}{6}, r_{i}=\frac{a}{2}
$$

From these equations, and $w_{i}=w_{j}=0$, we can obtain the equilibrium output levels, and $\alpha_{i}(i=1,2)$ as follows.

$$
w_{i}^{*}=w_{j}^{*}=0, r_{j}^{*}=\frac{a}{3}, r_{i}^{*}=\frac{a}{2}, q_{i}^{*}=\frac{a}{6}, q_{j}^{*}=\frac{a}{6}, \alpha_{i}^{*}=1, \alpha_{j}^{*}=\frac{3}{2} .
$$

The profits under $(N, D)$ are

$$
\pi_{i}=\frac{a^{2}}{12}, \pi_{j}=\frac{5 a^{2}}{36}-F, \quad \pi_{S}=0
$$

\section{B.3 No firm delegates}

Next, we consider the case in which no firm delegates to managers, that is, $\alpha_{i}=\alpha_{j}=1$.

The fourth stage In this case, the quantity of firm $i$ is equal to

$$
q_{i}(\boldsymbol{r})=\frac{a+r_{j}-2 r_{i}}{3}
$$


The second stage We obtain the best response function of each downstream firm:

$$
r_{j}=\frac{5 a-r_{i}}{10}, \quad(i, j=1,2, j \neq i)
$$

From these best response functions, we can obtain the equilibrium outcomes under the case that no firm delegates:

$$
w_{i}^{*}=w_{j}^{*}=0, r_{j}^{*}=\frac{5 a}{11}, q_{i}^{*}=\frac{2 a}{11} .
$$

The profits under $(N, N)$ are

$$
\pi_{i}=\pi_{j}=\frac{14 a^{2}}{121} \simeq 0.1157 a^{2}, \quad \pi_{S}=0
$$

\section{B.4 First stage}

We can derive the payoff matrix in the first stage (see Table 3).

\begin{tabular}{|l|rr|rr|}
\hline $1 / 2$ & \multicolumn{2}{|c|}{$D$} & \multicolumn{2}{c|}{$N$} \\
\hline \multirow{2}{*}{$D$} & \multicolumn{2}{|r|}{$203 a^{2} / 1849-F$} & \multicolumn{2}{c|}{$a^{2} / 12$} \\
& $203 a^{2} / 1849-F$ & $5 a^{2} / 36-F$ \\
\hline \multirow{2}{*}{$N$} & \multicolumn{2}{|r|}{$5 a^{2} / 36-F$} & \multicolumn{2}{c}{$14 a^{2} / 121$} \\
& $a^{2} / 12$ & & $14 a^{2} / 121$ \\
\hline
\end{tabular}

$D$ : Delegation; $N$ : No delegation.

Table 3: The first-stage decision: without the supplier

The equilibrium organizational forms are as follows: The outcome that both owners delegate is sustainable in equilibrium if and only if $F \leq 587 a^{2} / 22188$. The outcome that no owner delegates is sustainable in equilibrium if and only if $101 a^{2} / 4356 \leq F$. The two outcomes can be simultaneously sustainable in equilibrium if and only if $101 a^{2} / 4356 \leq$ $F \leq 587 a^{2} / 22188$. 


\section{Wholesale price discrimination by the monopo- listic supplier}

We suppose that the monopolistic supplier can price discriminate to the downstream firms.

\section{C.1 Both firms delegate}

The fourth stage The objective of the manager in firm $i$ is

$$
\begin{aligned}
g_{i} & =\alpha_{i} \Pi_{i}+\left(1-\alpha_{i}\right) R_{i} \\
& =\alpha_{i}\left\{\left(a-q_{i}-q_{j}-r_{i}-w_{i}\right) q_{i}+r_{j} q_{j}\right\}+\left(1-\alpha_{i}\right)\left(a-q_{i}-q_{j}\right) q_{i}
\end{aligned}
$$

We can obtain the best response function of firm $i$ 's manager as follows:

$$
q_{i}=\frac{a-q_{j}-\alpha_{i}\left(r_{i}+w_{i}\right)}{2}, \quad(i, j=1,2, j \neq i)
$$

Solving the simultaneous equations mentioned above, we obtain the quantity of firm $i$ :

$$
q_{i}(\boldsymbol{\alpha}, \boldsymbol{r}, \boldsymbol{w})=\frac{a-2 \alpha_{i}\left(r_{i}+w_{i}\right)+\alpha_{j}\left(r_{j}+w_{j}\right)}{3}
$$

The third stage We solve the owner's maximization problem and then obtain its best response function:

$$
\alpha_{i}\left(\alpha_{j}, \boldsymbol{r}, \boldsymbol{w}\right)=\frac{6\left(r_{i}+w_{i}\right)-a}{4\left(r_{i}+w_{i}\right)}-\frac{\alpha_{j}\left(r_{j}+w_{j}\right)}{4\left(r_{i}+w_{i}\right)}+\frac{3 r_{j}}{4\left(r_{i}+w_{i}\right)}, \quad(i, j=1,2, j \neq i)
$$

Solving the simultaneous equations above, we obtain $\alpha_{i}(\boldsymbol{r}, \boldsymbol{w})$

$$
\alpha_{i}(\boldsymbol{r}, \boldsymbol{w})=\frac{-a+8\left(r_{i}+w_{i}\right)-2\left(r_{j}+w_{j}\right)}{5\left(r_{i}+w_{i}\right)}+\frac{4 r_{j}-r_{i}}{5\left(r_{i}+w_{i}\right)}
$$

By substituting $\alpha_{i}(\boldsymbol{r}, \boldsymbol{w})$ into $q_{i}(\boldsymbol{\alpha}, \boldsymbol{r}, \boldsymbol{w})$, we can rewrite output as a function of $(\boldsymbol{r}, \boldsymbol{w})$ :

$$
q_{i}(\boldsymbol{r}, \boldsymbol{w})=\frac{2\left(a-3\left(r_{i}+w_{i}\right)+2\left(r_{j}+w_{j}\right)\right)}{5}+\frac{2 r_{i}-3 r_{j}}{5}
$$


The second stage The supplier and firms 1 and 2 set $w, r_{2}$, and $r_{1}$ to maximize their own profits. Solving the first-order conditions, we have the best response functions:

$$
\begin{aligned}
w_{i} & =\frac{2 a-4 r_{i}+\left(r_{j}+4 w_{j}\right)}{12}+\frac{4 w_{j}}{12} \\
& =\frac{2 a-4 r_{i}+r_{j}+8 w_{j}}{12}, \quad(i, j=1,2, j \neq i), \\
r_{j} & =\frac{7\left(a-\left(2 r_{i}+3 w_{i}\right)+2 w_{j}\right)}{34}+\frac{5\left(2 a+\left(r_{i}+4 w_{i}\right)-6 w_{j}\right)}{34} \\
& =\frac{17 a-\left(w_{i}+16 w_{j}+9 r_{i}\right)}{34}, \quad(i, j=1,2, j \neq i) .
\end{aligned}
$$

In this case, the equilibrium parameters are

$$
w_{i}^{*}=\frac{35 a}{121}, r_{j}^{*}=\frac{34 a}{121}, q_{i}^{*}=\frac{14 a}{121}, \alpha_{i}^{*}=\frac{79}{69}
$$

The profits under $(D, D)$ are

$$
\pi_{i}=\pi_{j}=\frac{812 a^{2}}{14641}-F \simeq 0.0555 a^{2}-F, \quad \pi_{S}=\frac{980 a^{2}}{14641} \simeq 0.0669 a^{2}
$$

\section{C.2 Only one firm delegates}

Now suppose that only firm $j$ delegates. We consider the third stage.

The third stage In this subgame, firm $i$ sets $\alpha_{i}=1$ in this stage. We can obtain $\alpha_{j}(1, \boldsymbol{r}, \boldsymbol{w})$ as

$$
\alpha_{j}=(1, \boldsymbol{r}, \boldsymbol{w})=\frac{-a+6\left(r_{j}+w_{j}\right)-\left(r_{i}+w_{i}\right)}{4\left(r_{j}+w_{j}\right)}+\frac{3 r_{i}}{4\left(r_{j}+w_{j}\right)} .
$$

We can rewrite the outputs as a function of

$$
\begin{aligned}
& q_{i}(\boldsymbol{r}, \boldsymbol{w})=\frac{a+2\left(r_{j}+w_{j}\right)-3\left(r_{i}+w_{i}\right)}{4}+\frac{r_{i}}{4}, \\
& q_{j}(\boldsymbol{r}, \boldsymbol{w})=\frac{a+\left(r_{i}+w_{i}\right)-2\left(r_{j}+w_{j}\right)}{2}-\frac{r_{i}}{2} .
\end{aligned}
$$


The second stage Using the quantities derived immediately above, we can obtain the supplier's best response functions as:

$$
\begin{aligned}
& w_{i}=\frac{a-2 r_{i}+2\left(r_{j}+w_{j}\right)}{6}+\frac{2 w_{j}}{6}=\frac{a-2 r_{i}+2 r_{j}+4 w_{j}}{6}, \\
& w_{j}=\frac{a-2 r_{j}+w_{i}}{4}+\frac{w_{i}}{4}=\frac{a-2 r_{j}+2 w_{i}}{4} .
\end{aligned}
$$

The best response functions of the downstream firms are:

$$
\begin{aligned}
& r_{j}=\frac{a-\left(2 r_{i}+3 w_{i}\right)+2 w_{j}}{6}+\frac{2\left(a+w_{i}-2 w_{j}\right)}{6}=\frac{3 a-2 w_{j}-w_{i}-2 r_{i}}{6} \\
& r_{i}=\frac{a-2\left(r_{j}+w_{j}\right)+w_{i}}{4}+\frac{a+2\left(r_{j}+w_{j}\right)-3 w_{i}}{4}=\frac{a-w_{i}}{2}
\end{aligned}
$$

We can obtain

$$
w_{i}^{*}=\frac{a}{3}, w_{j}^{*}=\frac{3 a}{10}, r_{j}^{*}=\frac{7 a}{30}, r_{i}^{*}=\frac{a}{3}, q_{i}^{*}=\frac{a}{10}, q_{j}^{*}=\frac{2 a}{15}, \alpha_{i}^{*}=1, \alpha_{j}^{*}=\frac{19}{16} .
$$

The profits under $(N, D)$ are

$$
\pi_{i}=\frac{37 a^{2}}{900} \simeq 0.0411 a^{2}, \pi_{j}=\frac{29 a^{2}}{450}-F \simeq 0.0644 a^{2}-F, \pi_{S}=\frac{11 a^{2}}{150} \simeq 0.0733 a^{2} .
$$

\section{C.3 No firm delegates}

Next, we consider the case in which no firm delegates to managers, that is, $\alpha_{i}=\alpha_{j}=1$.

The fourth stage The quantity of firm $i$ is equal to

$$
q_{i}(\boldsymbol{r}, \boldsymbol{w})=\frac{a+\left(r_{j}+w_{j}\right)-2\left(r_{i}+w_{i}\right)}{3} .
$$

The second stage Solving the first-order conditions of the maximization problem, we can obtain the supplier's best response functions as:

$$
w_{i}=\frac{a+\left(r_{j}+w_{j}\right)-2 r_{i}}{4}+\frac{w_{j}}{4}, \quad(i, j=1,2, j \neq i) .
$$


Similarly, we obtain the best response function of each downstream firm:

$$
r_{j}=\frac{5 a-4 w_{j}-w_{i}-r_{i}}{10}, \quad(i, j=1,2, j \neq i) .
$$

Using those best response functions, we can obtain the equilibrium wholesale prices and output levels as follows.

$$
w_{i}^{*}=\frac{6 a}{17}, r_{j}^{*}=\frac{5 a}{17}, q_{i}^{*}=\frac{2 a}{17} .
$$

The profits under $(N, N)$ are

$$
\pi_{i}=\pi_{j}=\frac{14 a^{2}}{289} \simeq 0.0484 a^{2}, \quad \pi_{S}=\frac{24 a^{2}}{289} \simeq 0.0830 a^{2}
$$

\begin{tabular}{|c|c|c|}
\hline $1 / 2$ & $D$ & $N$ \\
\hline \multirow{2}{*}{$D$} & $0.0555 a^{2}-F$ & $0.0411 a^{2}$ \\
\hline & $0.0555 a^{2}-F$ & $0.0644 a^{2}-F$ \\
\hline \multirow{2}{*}{$N$} & $0.0644 a^{2}-F$ & $0.0484 a^{2}$ \\
\hline & $0.0411 a^{2}$ & $0.0484 a^{2}$ \\
\hline
\end{tabular}

\section{C.4 First stage}

We can derive the payoff matrix in the first stage (see Table 4).

$D$ : Delegation; $N$ : No delegation.

Table 4: The first-stage decision: different input prices by the supplier

The equilibrium organizational forms are as follows: The outcome that both owners delegate if and only if $F<0.0144 a^{2}$; Only one of the owners delegates if and only if $0.0144 a^{2}<F<0.016 a^{2} ;$ No owner delegates if and only if $0.016 a^{2}<F$. 